\title{
AÇÕES DE CONSERVAÇÃO E PRESERVAÇÃO DA MEMÓRIA NO CONTEXTO DIGITAL
}

\section{CONSERVATIONAND PRESERVATIONACTIONS IN THE DIGITAL CONTEXT}

Wilza Aurora Matos TEIXEIRA ${ }^{1}$

RESUMO

Mostra as iniciativas que vêm surgindo para preservação da memória nacional, adequando os acervos para novos formatos e utilizando os recursos das novas tecnologias da informação para disponibilizar nossos acervos em formato digital. Apresenta diretrizes para uma política de preservação e conservação de nossa memória .

Palavras-chave: memória nacional, novas tecnologias, cidadania, globalização, Internet, Disseminação da informação.

\begin{abstract}
This study displays the beginning for the preservation of the Brazilian memory. The principal points in the politics of our memory preservation and with the use of new technologies are also presented.
\end{abstract}

Key words: national memory, human rights, globalization, Internet, information dissemination.

Atualmente o tema memória compõe o corpus cidadania. Políticas de preservação de nossa memória têm sido priorizada em nossas Universidades (Projeto SUARQH, Unicamp, USP e UNESP, Projeto Infra da FAPESP, dentre outros). Iniciativas como o Projeto Portinari, que se dedica ao registro fotográfico das obras atribuídas ao pintor Cândido Portinari, desde o menor esboço até os grandes afrescos, passando por exemplares avulsos de gravuras e dos documentos referentes a sua obra, vida e época contam com os apoios da PUC-Rio, FAPERJ, Petrobrás, IBM, Fundação VITAE e Associação Cultural Cândido Portinari, e resultaram em um importante arquivo multimídia sobre o processo histórico cultural brasileiro das décadas de 1920 a 1960.

Com a globalização, os conteúdos veiculados na rede vêm crescendo na área de negócios

\footnotetext{
(1) Especialista em Novas Tecnologias da Informação - UNESP - Marília - SP. Câmara Municipal de Marília. R. Pedro Faria de Moraes, 200, 17516-400, Marília, SP, Brasil. E-mail: wamt@terra.com.br
} 
eletrônicos, porém, os conteúdos que veiculam nossa identidade cultural, ainda são praticamente desconhecidos dos usuários e não tão facilmente localizados na rede. As informações que hoje são veiculadas e que retratam nossa identidade cultural são produzidas e armazenadas de forma descentralizada e dispersa. Reunir e incorporar estas informações como produtos e serviços demanda um grande esforço. Algumas dificuldades como alto custo da digitalização de acervos, escolhas de formatos na preparação da base de dados, maior apoio à pesquisa em tecnologia de produção e comunicação dos conteúdos e da criação de condições para a capacitação universal dos cidadãos para o uso das novas tecnologias deverão ser superados para construção de uma Sociedade de Informação democrática.

Nossas Instituições de guarda da produção intelectual ou artística deixada pelo homem em sua trajetória espacial e cultural como os Museus, Bibliotecas e Arquivos têm em comum a responsabilidade na preservação destes acervos e no processo de recuperação da informação em benefício da pesquisa científica que por sua vez irá reconstruir vestígios de atividades sociais que se foram, para que estas não se percam.

Nesse sentido, sobressai-se o papel do historiador como responsável pela elaboração de uma história crítica, bem como o de estabelecer ou restabelecer os vínculos existentes entre a história e a memória e a atribuição de retirar do documento a consciência da sociedade na qual se insere não se limitando apenas ao discurso do poder que o gerou (PETRATI, p.2).

Desta forma, amplia-se a noção de documento tornando-o mais abrangente e complexo e a multiplicação dos registros tanto quanto a necessidade de estudo de novos suportes em função das transformações tecnológicas bem como da sua guarda e preservação impõem-se como objeto de reflexão.

As Instituições de guarda (bibliotecas, museus, dentre outros), são pontos focais naturais para difusão, captação e processamento de conteúdos de interesse. $\mathrm{O}$ acesso deve ser facultado em formato digital para permitir consultas de forma mais fácil e eficiente. Ampliar as oportunidades de acesso aos serviços e produtos disponíveis, estender seu uso a outros grupos sociais, aumentando as potencialidades de criação de conteúdos locais, conteúdos veiculadores ou construtores de nossa identidade cultural. Vale observar que é fundamental que se criem mecanismos de incentivo à produção de conteúdos que expressem a cultura das mais diversas regiões do país, bem como daqueles grupos que se identificam por áreas de interesse profissional, de negócios, de lazer, de hobby e até mesmo de caráter contestatório e de contracultura. Sites como o UOL, no âmbito do setor privado, tem facilitado bastante a disseminação da língua portuguesa e a familiarização do usuário com o ambiente Internet. Por isto, é importante o desenvolvimento de interfaces que possibilitem ao cidadão uma interação amigável com meio de acesso facilitado.

Para sua inserção no contexto da sociedade de informação, o país não poderá incorrer no erro de privilegiar apenas as formas identitárias pelo culto à memória e das origens, pois tão ou mais importante que a identidade vinculada ao passado é a identidade que se projeta para o futuro. Alguns pontos importantes para a sociedade são:

- Registrar de forma sistemática a produção científica e tecnológica, para facilitar a disseminação e ampliação dos resultados dos esforços das pesquisas;

- Registrar as manifestações culturais nas diferentes mídias, para preservar e manter vivas as origens da nação brasileira, em seus aspectos multiétnicos e multiculturais;

- Criar mecanismos para a produção de conteúdos por parte da comunidade. A produção e o uso de conteúdos que reflitam os interesses e explorem a diversidade da riqueza cultural em todos os espaços, de áreas periféricas e rurais, de minorias e de grupos com interesses afins devem ser apoiados, como forma de reduzir as disparidades regionais e sociais, abrindo oportunidade para todos os tipos de registro e difusão de manifestações e idéias;

- Promover a igualdade de oportunidades de acesso às novas tecnologias, principalmente para os cidadãos de menor poder aquisitivo, para 
analfabetos, pessoas com necessidades especiais e outros setores marginalizados.

Algumas ações indutoras, tais como: promover a criação e organização de sites, páginas e portais de interesse comunitário que sirvam de referência cultural sobre os nossos municípios, distritos, povoados, e mesmo bairros periféricos, como forma de organização e ação cultural; instruir um programa de digitalização de obras de valor histórico: patrocinar o inventário e a digitalização de obras literárias, manuscritos, gravuras e todo o material iconográfico sobre o Brasil dos diferentes períodos históricos, como meio de resgate da memória da formação nacional.

A globalização não trata apenas das relações internacionais puramente comerciais, ela perpassa valores que muitas vezes, parecem por em risco nossa identidade cultural, pois homogeneiza os valores atuais e cria novos valores, principalmente de consumo, ocasionando a perda de valores humanos e de cidadania. Pensar o passado, nos dará subsídios para projetar no futuro a construção da identidade cultural que queremos inserire difundir no mundo globalizado. O maior patrimônio de um povo é sua memória.

Os profissionais destas áreas como os bibliotecários, arquivistas, museólogos, entre outros, tem a responsabilidade neste processo de transformação de suportes da matéria-prima, a informação, e em sua divulgação, em benefício da divulgação científica, social, tecnológica e cultural. Para SANTOS (1996):

O Moderno Profissional da Informação, exercerá um papel fundamental no processo de transmissão, intermediação, e disseminação da informação trabalhando remotamente, gerenciando bibliotecas virtuais, utilizando a Internet como um meio de fazer com que recursos e esforços sejam unidos, para que seja criado um acervo universal e totalmente compartilha-do.

Tendo como objetivo a construção de nossa identidade cultural, trabalhar com esta diversidade de material documental, torna-se na entrada deste novo milênio, um grande desafio.

\section{REFERÊNCIAS}

PETRATI, P. Os documentos e a memória social. Jornal Diário de Marília, Marília, 2000.p.2.

SANTOS, J.P. O moderno profissional da informação: o Bibliotecário e seu perfil face aos novos tempos. In: V Encontro de Escolas de Biblioteconomia da Região Sul, 5., 1996. Palestra... Londrina, 1996. 
